\title{
Palaeoclimate
}

\section{Lags within the Younger Dryas}

\author{
A slowing Atlantic overturning circulation during the last deglacial warming \\ caused abrupt cooling in the Northern Hemisphere. Lake sediment record suggests \\ that hydrological change in Europe lagged the temperature drop by almost 200 \\ years.
}

\section{Ana Moreno}

An abrupt cooling event, the Younger Dryas, interrupted the warming after the end of the last glacial period. The cool interlude, approximately 12,800 years ago, was triggered by a slowdown of overturning circulation in the North Atlantic, and can be identified in climate reconstructions across the Northern Hemisphere ${ }^{1}$ and parts of the Southern Hemisphere ${ }^{2}$. In Europe, the Younger Dryas was accompanied by substantial shifts in vegetation ${ }^{3}$, as well as a drop in temperature. Writing in Nature Geoscience, Rach and colleagues ${ }^{4}$ demonstrate that in Western Europe, the vegetation change was caused by a shift in the hydrologic cycle, which was probably related to the build-up of sea ice in the northern Atlantic Ocean.

The onset of the Younger Dryas was linked to the release of freshwater to the northern Atlantic Ocean, which caused deep water formation to slow ${ }^{5}$ and led to the development of extensive winter sea-ice cover ${ }^{6}$. In addition, the westerly wind belt that circles the mid-latitudes of the Northern Hemisphere shifted southward ${ }^{7}$. Both temperature and humidity decreased over continental Europe ${ }^{8-10}$. It has been unclear, however, whether the Younger Dryas environmental change in Europe occurred simultaneously with the cooling as recorded in Greenland ${ }^{11}$, or lagged Greenland cooling by up to 200 years $^{7}$, given the dating uncertainties of both the Greenland and European records.

Rach and colleagues ${ }^{4}$ use a well-dated, annually resolved sediment core from the Lake Meerfelder Maar in western Germany to assess the timing and characteristics of environmental change in Europe. They measured the hydrogen isotopes $(\delta \mathrm{D})$ of aquatic and terrestrial lipid biomarkers at a resolution of less than a decade. Hydrogen isotope compositions as recorded by vegetation are influenced by both temperature and the $\delta \mathrm{D}$ of precipitation $^{12}$, which in turn is controlled by the moisture source.

The $\delta \mathrm{D}$ values of both the terrestrial and aqueous lipid records drop abruptly about 12,846 years ago, which Rach and colleagues interpret as a change in temperature that occurred in synchrony with the cooling in Greenland. A second decline in $\delta \mathrm{D}$ values occurs 170 years later, and is mainly seen in the aquatic lipids. The authors suggest that this second decline reflects a change in the source and pathway of moisture reaching the site, as well as a decrease in the overall amount of moisture in the region - an inference that is supported by the observed increase in proxies for evaporation. 
The results reconcile the timing of environmental change seen in European lake records with the Greenland ice core results ${ }^{4}$. They suggest a common cooling across the northern mid to high latitudes, followed by a massive atmospheric reorganization 170 years later that triggered prominent ecological changes in Central Europe previously identified from pollen records ${ }^{7}$. Rach and colleagues suggest the reorganisation reflects the southward displacement of the westerly wind belt in response to the build-up of sea ice in the northern Atlantic. They also highlight the crucial role of hydrology in amplifying environmental change during periods of abrupt temperature change -this amplification is all too often overlooked. These results also show the danger in assuming that events in records subject to age model uncertainties are synchronous.

Even though Rach and colleagues ${ }^{4}$ have demonstrated that environmental change in Western Europe occurred 170 years after cooling, these changes nevertheless happened rapidly. This work highlights the potential for rapid environmental change to take place over the course of just a few human lifetimes.

Ana Moreno is at the Pyrenean Institute of Ecology - CSIC, Zaragoza, Spain

e-mail: amoreno@ipe.csic.es

References

1. Broecker, W. et al. Quat. Sci. Rev. 29, 1078-1081 (2010).

2. Griffiths, M. et al. Earth Plan. Sci. Lett. 295, 30-36 (2010).

3. Birks, H.J.B. \& Ammann, B. Proc. Natl Acad. Sci. 97, 1390- 1394 (2000).

4. Rach, O et al. Nature Geosci. 7, 109-112 (2014).

5. Pinter, N. et al. Earth Sci. Rev. 106, 247-264 (2011).

6. Hillaire-Marcel, C. et al. Quat. Sci. Rev. 79, 184-190 (2013).

7. Brauer, A. et al. Nature Geosci. 1, 520-523 (2008).

8. Heiri, O. \& Lotter, A.F. Boreas 34, 506-516 (2005).

9. Litt, T. et al. Quat. Int. 61, 5-16.

10. Lane, C. S. et al. Geology 41, 1251-1254 (2013)

11. Rassmussen, S. O. et al. J. Geophysical Research 111, D06102 (2006).

12. Sachse, D. et al. Ann. Rev. Earth Plan. Sci. 40, 221-249 (2012).

\section{Figure caption}

Lake Meerfelder Maar, Germany. Rach and colleagues ${ }^{4}$ analyzed the hydrogen isotope composition of lipids in sediments from this lake, to show that a shift in vegetation occurred 170 years after temperatures first fell during the Younger Dryas. They suggest that the vegetation change was instead linked to a change in the source and amount of moisture reaching the region. ] 